\title{
Alternative methods for functional assessment of intermediate coronary lesions
}

\author{
Martyna Zaleska ${ }^{1}$, Łukasz Kołtowski ${ }^{1}$, Jakub Maksym ${ }^{1}$, Mariusz Tomaniak ${ }^{1}$, \\ Maksymilian Opolski ${ }^{2}$, Janusz Kochman ${ }^{1}$ \\ ${ }^{1} 1^{\text {st }}$ Chair and Department of Cardiology, Warsaw Medical University, Warsaw, Poland \\ ${ }^{2}$ Department of Interventional Cardiology and Angiology, Cardinal Wyszynski \\ National Institute of Cardiology, Warsaw, Poland
}

\begin{abstract}
Wire-based fractional flow reserve (FFR) is a diagnostic tool used to evaluate the ischemic burden of coronary lesions. Large-scale studies have shown that FFR-guided revascularization is associated with better clinical outcomes. However, wide adoption of this technology is limited due to the considerable cost, additional time needed for set-up and performance of the measurement as well as the invasiveness of the procedure which requires pressure wire placement across the lesion into the distal segment of the coronary artery. To overcome these limitations new, promising, and less-/non-invasive methods were developed. These methods are based on computational fuid dynamics analysis and three-dimensional lumen reconstruction. The aim of this paper is to review scientific evidence supporting the clinical safety and efficacy of these techniques, such as instantaneous wave-free ratio, quantitative flow ratio and FFR calculated from computed tomographic angiography. (Cardiol J 2020; 27, 6: 825-835)
\end{abstract}

Key words: coronary angiography, quantitative flow ratio, computational fluid dynamics, fractional flow reserve

\section{Introduction}

Coronary artery disease (CAD) is one of the main causes of morbidity and mortality in developed countries $[1,2]$. Coronary angiography remains the gold standard for the diagnosis of CAD, however, its ability to differentiate ischemic from non-ischemic lesions is limited. In this respect, fractional flow reserve (FFR), which takes into consideration the functional severity of coronary stenosis, outperforms the traditional diagnostic approach, based solely on morphometric assessment [3, 4]. Unfortunately, the adoption of FFR in everyday clinical practice is slow and is utilized in only a minority of centers [5, 6]. Härle et al. [7] found that FFR was used in $3.2 \%$ of all diagnostic procedures performed in Germany. In Poland pen- etration rate of FFR was even lower and did not exceed $2 \%$ in 2014 [8]. The main limiting factors include: 1) considerable time need for set-up and conduction of the examination; 2) high cost of diagnostic probe and adenosine infusion; 3 ) invasiveness, as it requires insertion of a pressure wire across the lesion into the distal part of the vessel, which is associated with increased risk of serious complications, e.g. ventricular arrhythmias and coronary vessel dissection (occurring in $0.5 \%$ of procedures), and 4) patient-related contraindications (hypotension, asthma, seconddegree atrioventricular blocks) [9-11]. To overcome these limitations, less invasive techniques based on computational fluid dynamics (CFD) and three-dimensional (3D) lumen reconstruction have been proposed [12-16].

Address for correspondence: Łukasz Kołtowski, MD, PhD, First Chair and Department of Cardiology, Medical University of Warsaw, ul. Banacha 1a, 02-097 Warszawa, Poland, tel: +48 501418 951, e-mail: lukasz@koltowski.com 


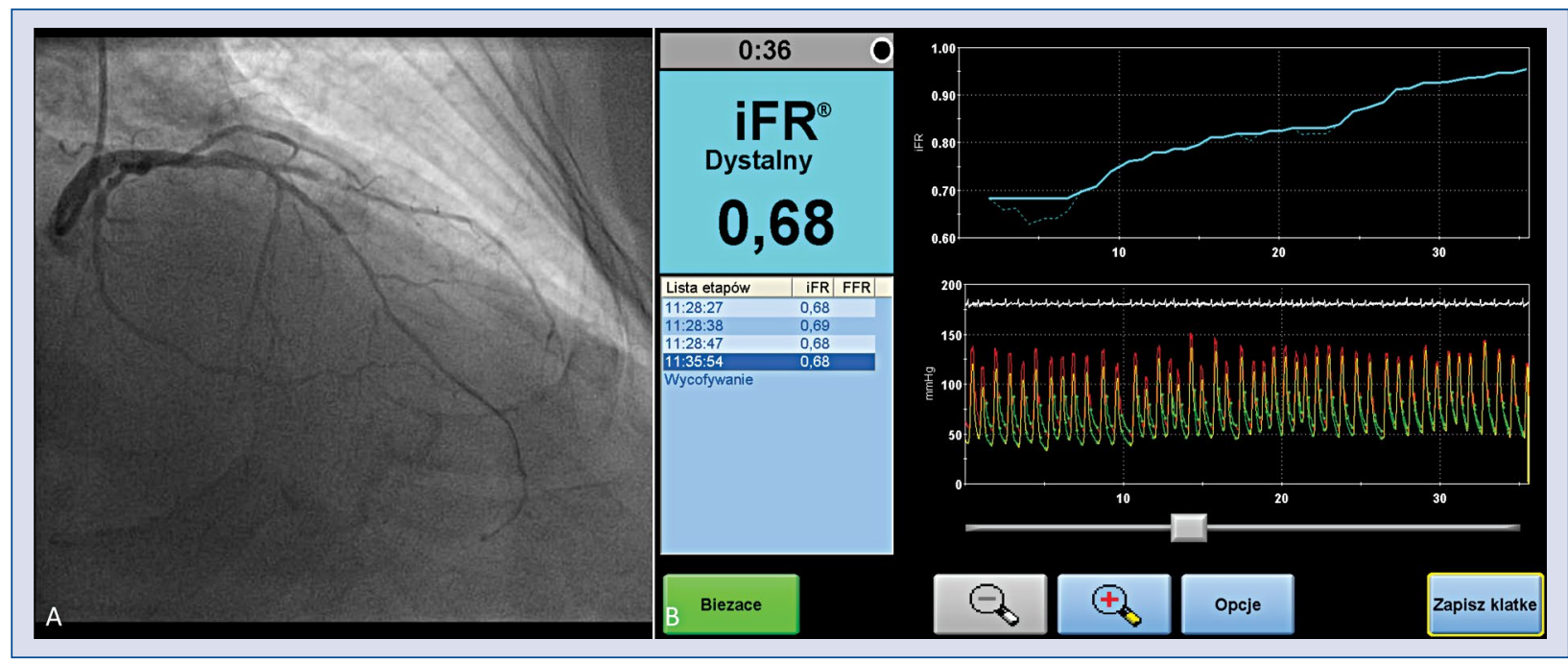

Figure 1. Vessel evaluation with instantaneous wave-free ratio (iFR) method indicates significant lesion in left anterior descending $(L A D)$ artery (iFR $=0.68)$; A. Coronary angiogram with wire position in distal LAD; B. The iFR with pullback recording using ScoutTM software.

\section{Pressure wire methods}

\section{Instantaneous wave-free ratio}

Instantaneous wave-free ratio (iFR) is one alternative method that does not require adenosine infusion (Fig. 1). Although vessel wiring is still necessary, iFR measurements are quicker to perform and are cheaper than FFR. The scientific basis came from findings by Sen et al. [17] who demonstrated that functional assessment of coronary lesions comparable to FFR is possible without drug induced hyperemia, during the socalled "wave-free period". This period is seen in diastole and characterized by minimal and stable coronary resistance (similar to "hyperemic-like" conditions), which makes the trans-stenotic pressure gradient corresponding directly to flow and lesion severity [17].

The first published clinical study evaluating the correlation between iFR and FFR (ADenosine Vasodilator Independent Stenosis Evaluation [ADVISE]) demonstrated a close correlation between values obtained with these two methods $(r=0.9$; $\mathrm{p}<0.001)$ [17]. The possibility of iFR real-time measurement was proven by ADVISE in-practice study. The authors assessed 392 angiographically intermediate lesions and demonstrated that the best cutoff value of iFR corresponding to FFR $\leq 0.80$ was an $\mathrm{iFR} \leq 0.90$ and resulted in classification agreement in $80 \%$ of cases, specificity of $79 \%$, sensitivity of $81 \%$, positive predictive value (PPV) of $71 \%$ and negative predictive value (NPV) of $87 \%$ [18]. What is more, it was shown that iFR correlates more closely than FFR with coronary flow velocity reserve, which suggests that iFR may be a more physiological parameter of disease severity [19].

In 2017, two pivotal trials evaluating iFR in clinical practice were published. The Functional Lesion Assessment of Intermediate Stenosis to Guide Revascularization (DEFINE-FLAIR) trial consisting of almost 2500 patients with stable CAD, proved that iFR-guided is noninferior to FFR-guided coronary revascularization with respect to composite risk of death from any cause, nonfatal myocardial infarction (MI) or unplanned revascularization during 1-year follow-up. Additionally, study results showed that in iFR group median procedural time was significantly shorter $(40.5$ vs. 45 min; $p=0.001$; iFR vs. FFR, respectively) and fewer patients had adverse procedural symptoms ( $3.1 \%$ vs. $30.8 \%$; $p<0.001$; iFR vs. FFR, respectively) [20]. The Instantaneous Wave-free Ratio versus Fractional Flow Reserve in Patients with Stable Angina Pectoris or Acute Coronary Syndrome (iFR-SWEDE-HEART) trial consisting of over 2000 patients with stable CAD or acute coronary syndrome $(17.5 \%$ patients $)$ showed similar results. The primary composite end-point (defined as composite of death from any cause, nonfatal MI or unplanned revascularization) occurred in $6.7 \%$ of the patients in the iFR group and in $6.1 \%$ of the patients in the FFR group in 1-year follow-up ( $\mathrm{p}=0.007$ for noninferiority). 
Authors, just as in the previously described study, reported that chest discomfort occurred less often during the iFR-guided procedure (3.0\% vs. $68.3 \%$; $\mathrm{p}<0.001$ ) [21]. Results of these two trials were reflected in European and in American guidelines, in which iFR was regarded as equivalent to FFR in hemodynamic assessment of intermediate-grade stenosis $[22,23]$.

\section{Alternative pressure wire methods}

Over the years other adenosine-free methods based on assessment of diastolic resting indices have been proposed. Recently published data proved a high correlation between iFR and resting distal coronary to aortic pressure $\left(\mathrm{P}_{\mathrm{d}} / \mathrm{P}_{\mathrm{a}}\right)$. Both were associated with lesion anatomic and hemodynamic severity, showing excellent agreement between them $[24,25]$. It seems that the adoption of $\mathrm{P}_{d} / \mathrm{P}_{\mathrm{a}}$ could be easier, in comparison to iFR, it was analyzable in a significantly higher number of cases [25]. Other diastolic resting indexes included resting $\mathrm{P}_{\mathrm{d}} / \mathrm{P}_{\mathrm{a}}$ during the complete duration of diastole, in $25 \%$ to $75 \%$ of diastole, at midpoint of diastole (Fig. 2). All the above-mentioned parameters were proven to be identical to iFR, not only numerically, but also with respect to their agreement to FFR [26]. Though, they are all very promising, further studies are needed to evaluate their clinical value.

\section{Computational-based methods}

\section{Quantitative flow ratio}

In 2013 Morris et al. [13] published results from the VIRTUal FFR From Coronary Angiography (VIRTU-1) study, designed to demonstrate the feasibility of FFR computations based solely on two-dimensional (2D) coronary angiography images (virtual FFR [vFFR]). The study population consisted of 19 patients. Compared to FFR, vFFR had an accuracy of $97 \%$, sensitivity of $86 \%$, specificity of $100 \%$, PPV of $100 \%$, and NPV of $97 \%$. Although, there was a strong correlation between vFFR and wire-based FFR ( $r=0.84)$, the image analysis was labor- and time-consuming, requiring $24 \mathrm{~h}$ to process the above-mentioned data. Of note, authors used a "one-size fits all" approach, which assumed constant coronary vessel resistance. Such an assumption carries the risk of stenosis misclassification due to possible changes in downstream microcirculatory resistance [13].

Papafakis et al. [27] proposed virtual functional assessment index (vFAI) - a quick method of

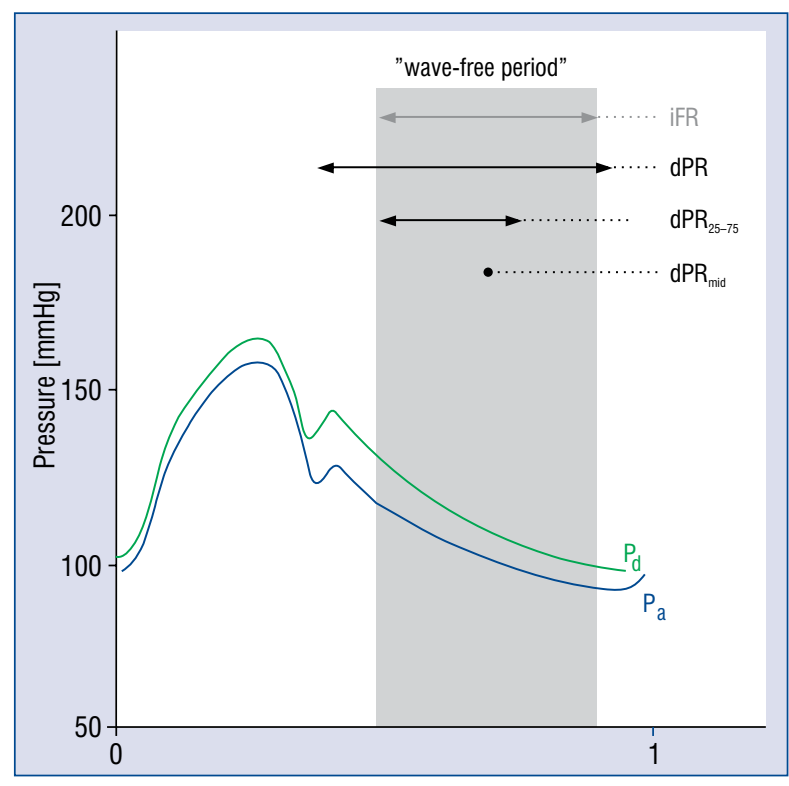

Figure 2. Resting $\mathrm{Pd} / \mathrm{Pa}$ ratios over different periods of diastole. Based on [26]. Pd - resting distal coronary pressure; $\mathrm{Pa}$ - aortic pressure; $\mathrm{Pd} / \mathrm{Pa}$ - resting distal coronary to aortic pressure; iFR — instantaneous wave-free ratio; $\mathrm{dPR}-\mathrm{Pd} / \mathrm{Pa}$ during the complete duration of diastole; $\mathrm{dPR}_{25-75}-\mathrm{Pd} / \mathrm{Pa}$ in $25 \%$ to $75 \%$ of diastole; $\mathrm{dPR}_{\text {mid }}-\mathrm{Pd} / \mathrm{Pa}$ in midpoint of diastole.

functional assessment of intermediate coronary lesions, which took only $15 \mathrm{~min}$ to analyze one vessel. This approach computes distal to proximal pressure ratio over the lesion based on $3 \mathrm{D}$ quantitative coronary angiography $(\mathrm{QCA})$ reconstruction and steady-flow CFD. The method was compared to FFR in 120 patients showing accuracy of $88 \%$, sensitivity of $90 \%$ and specificity of $86 \%$ for the optimal vFAI cut-off point $(\leq 0.82)$. Additionally, the $\mathrm{vFAI}$ was superior to $3 \mathrm{D} \mathrm{QCA}$ in predicting hemodynamic significance of coronary stenosis and demonstrated close correlation and good agreement with wire-based FFR values. The main limitation of vFAI, which is based solely on lesion geometry, is the fact that it does not take into account microvascular resistance and size of myocardial territory subtended by the vessel [27].

To overcome these limitations, the computed $\mathrm{FFR}\left(\mathrm{FFR}_{\mathrm{QCA}}\right)$ based on mean volumetric flow rate at hyperemia derived from $3 \mathrm{D}$ vessel invasive coronary angiography (ICA) reconstruction, Thrombolysis in Myocardial Infarction (TIMI) frame count and CFD utilization was proposed (Fig. 3). The analysis of 77 vessels provided an $88 \%$ overall accuracy of $\mathrm{FFR}_{\mathrm{QCA}}$ for diagnosis of ischemia (defined as FFR $\leq 0.8$ ). There was a strong correla- 


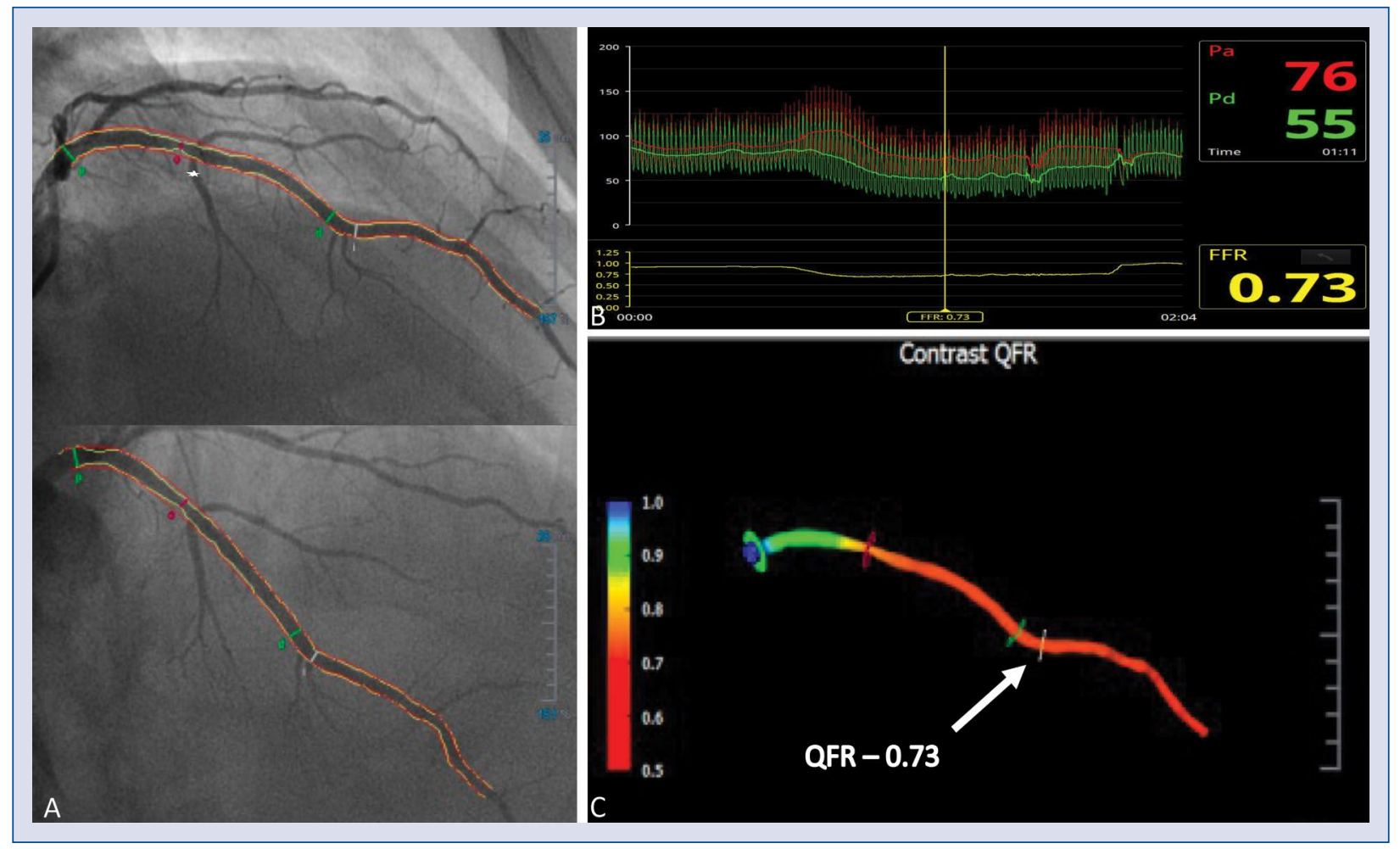

Figure 3. Computation of quantitative flow ratio (QFR) from coronary angiography; A. Angiographic projections of the left anterior descending (LAD) artery at $>25^{\circ}$ apart; $B$. Fractional flow reserve (FFR) measured during intravenous adenosine infusion was 0.73; C. Computed QFR value indicates ischemia (QFR $=0.73$ ). Arrow indicates original location of pressure transducer.

tion between $\mathrm{FFR}_{\mathrm{QCA}}$ and $\mathrm{FFR}$ values $(\mathrm{r}=0.81$, $\mathrm{p}<0.001)$ with a mean difference of \pm 0.06 $(\mathrm{p}=0.054)[12]$.

One of the main advantages of this method is short computation time, which did not exceed $10 \mathrm{~min}$ in total processing. Additionally, this method provides an evaluation of the entire coronary tree, whereas in wire-based FFR, only those lesions in which a pressure wire is inserted can be assessed [28].

Further confirmation of diagnostic accuracy of fast computational approaches came from prospective, observational, multicenter Functional Assessment by Various Flow Reconstruction (FAVOR) pilot study, in which 3 different quantitative flow ratio (QFR) computations were compared with standard wire-based FFR measurements. These included: 1) fixed-flow QFR (fQFR) that assumed a universal hyperemic flow velocity of $0.35 \mathrm{~m} / \mathrm{s}$ ); 2) contrast-flow QFR (cQFR) based on individual virtual flow derived from the frame count during contrast injection; 3 ) adenosine-flow (aQFR) based on individual virtual flow derived from the frame count during maximal adenosine-induced hyperemia. Authors confirmed good agreement between wire-based FFR and each QFR computation. The diagnostic accuracy was comparable for cQFR (86\%) and aQFR (87\%) and was significantly higher compared to fQFR (80\%) indicating that the use of adenosine is not needed in this method [29]. Recently QFR received Conformité Européenne (CE) certificate, allows for wider adoption to everyday clinical practice.

In 2017, results from The FAVOR II China (Functional Diagnostic Accuracy of Quantitative Flow Ratio in Online Assessment of Coronary Stenosis) study were also published. They prospectively enrolled 308 consecutive patients at 5 centers in China. The primary endpoint was to assess if QFR would improve diagnostic accuracy of coronary angiography. Authors met the prespecified performance goal for level of diagnostic accuracy of QFR in identifying hemodynamically significant stenosis. Additionally, they confirmed QFR to have $94.6 \%$ sensitivity, $91.7 \%$ specificity, 85.5\% PPV, and $97.1 \%$ NPV and diagnostic accuracy of $92.4 \%$ in patient-level analysis, and $92.7 \%$ in vessel-level analysis [30]. 
A recently published study demonstrated retrospectively analyzed results of 306 intermediate lesions, which had been previously evaluated using FFR. In contradiction to previous studies, which utilized core-lab assessment, in this particular study used an on-site QFR calculation in all cases. It showed that the Pearson correlation was strong for QFR $(r=0.85)$. Additionally, optimal QFR decision value of 0.79 was identified, this corresponded to $\mathrm{FFR}=0.80(\mathrm{AUC}=0.94)$. After introduction of the cut-off value of $\leq 0.74$ and $>0.83$, an excellent diagnostic performance of QFR was achieved, with sensitivity and specificity $>95 \%$. Additionally, it was confirmed that the time for QFR analysis was relatively short and substantially decreased with the number of analyzed cases. The first 50 QFR analysis took an average of 5 min $59 \mathrm{~s}$, whereas in the final 50 cases the mean time was $2 \min 7 \mathrm{~s}$ [31].

Westra et al. [32] prospectively evaluated QFR in 240 lesions and correctly classified $83 \%$ of the lesions when an FFR cut off value of 0.8 was used. They also achieved a sensitivity of $77 \%$, specificity of $86 \%$, PPV of $87 \%$, and NPV of $75 \%$.

In 2018 the results from The FAVOR II Europe-Japan Study were published. In this international, multicenter trial 329 patients were enrolled. QFR values were calculated online in catherization laboratories during the procedure. Sensitivity and specificity were $>86 \%$ for QFR, which was significantly higher than for $2 \mathrm{D}$ QCA (sensitivity $44.2 \%$; $\mathrm{p}<0.001$ and specificity $76.5 \% ; \mathrm{p}=0.002$ ) [33].

The most recently published study demonstrated that QFR may also be utilized in acute coronary syndrome settings, particularly in guiding non-culprit lesion revascularization in patients presenting with ST-segment elevation MI [34]. Additionally, the QFR good inter-core laboratory reproducibility had already been proven [35].

Although QFR is a very promising method, there are some technical limitations that should be taken into account. At present, the degree of flow-limiting stenosis of the ostial left main and ostial right coronary artery lesions cannot be reliably measured. Supraventricular tachyarrhythmia leading to an altered filling pattern of coronary arteries remains an exclusion criterion for $\mathrm{FFR}_{\mathrm{QCA}}$ calculation. Additionally, patients with coronary artery bypass grafting supplying evaluated vessels or with collateral circulation have not been adequately studied [12]. Last, the timing of contrast injection may also affect the $\mathrm{FFR}_{\mathrm{QCA}}$ values.

Additionally, data on clinical outcomes i.e. patient quality of life and cost-effectiveness remains lacking. This gap may will hopefully be addressed

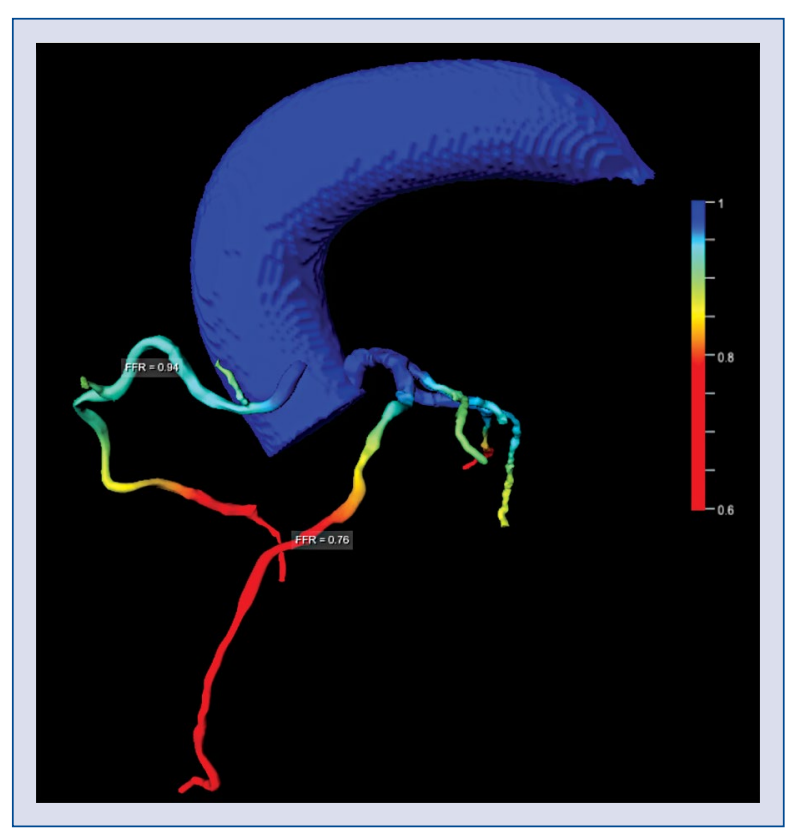

Figure 4. Coronary computed tomography angiography-derived fractional flow reserve indicates no ischemia in right coronary artery with computed value of 0.94 , and hemodynamically significant lesion in left anterior descending artery with measured value of 0.76 [Image by courtesy of Drs. Christian Tesche and Maksymilian P. Opolski].

by the upcoming FAVOR III trial, which is designed as a prospective, randomized, multicenter clinical outcome study. With a planned enrollment of approximately 2000 patients, it is powered to establish the role of this method in the diagnostic process of CAD patients.

\section{Computed tomographic angiography}

Computed tomographic angiography (CTA) of the coronary vessels was the first non-invasive diagnostic imaging method providing data for CFD analysis to derive FFR-equivalent measurements (Fig. 4). Koo et al. [14] analyzed 103 patients, who underwent coronary CTA, QCA and FFR measurement. They performed the computation of FFR from coronary CTA $\left(\mathrm{FFR}_{\mathrm{CT}}\right)$ using a powerful supercomputer to calculate the above-mentioned values. The proposed method utilized semi-automated segmentation of coronary arteries and approximation of the left ventricular mass. Despite the high computing power, a single analysis took approximately $5 \mathrm{~h}$. The $\mathrm{FFR}_{\mathrm{CT}}$ had an accuracy of $84.3 \%$, sensitivity of $87.9 \%$, specificity of $82.2 \%$, PPV of $73.9 \%$, and NPV of $92.2 \%$ for the diagnosis of ischemia-inducing lesions on a per-vessel basis. Additionally, there was a good 


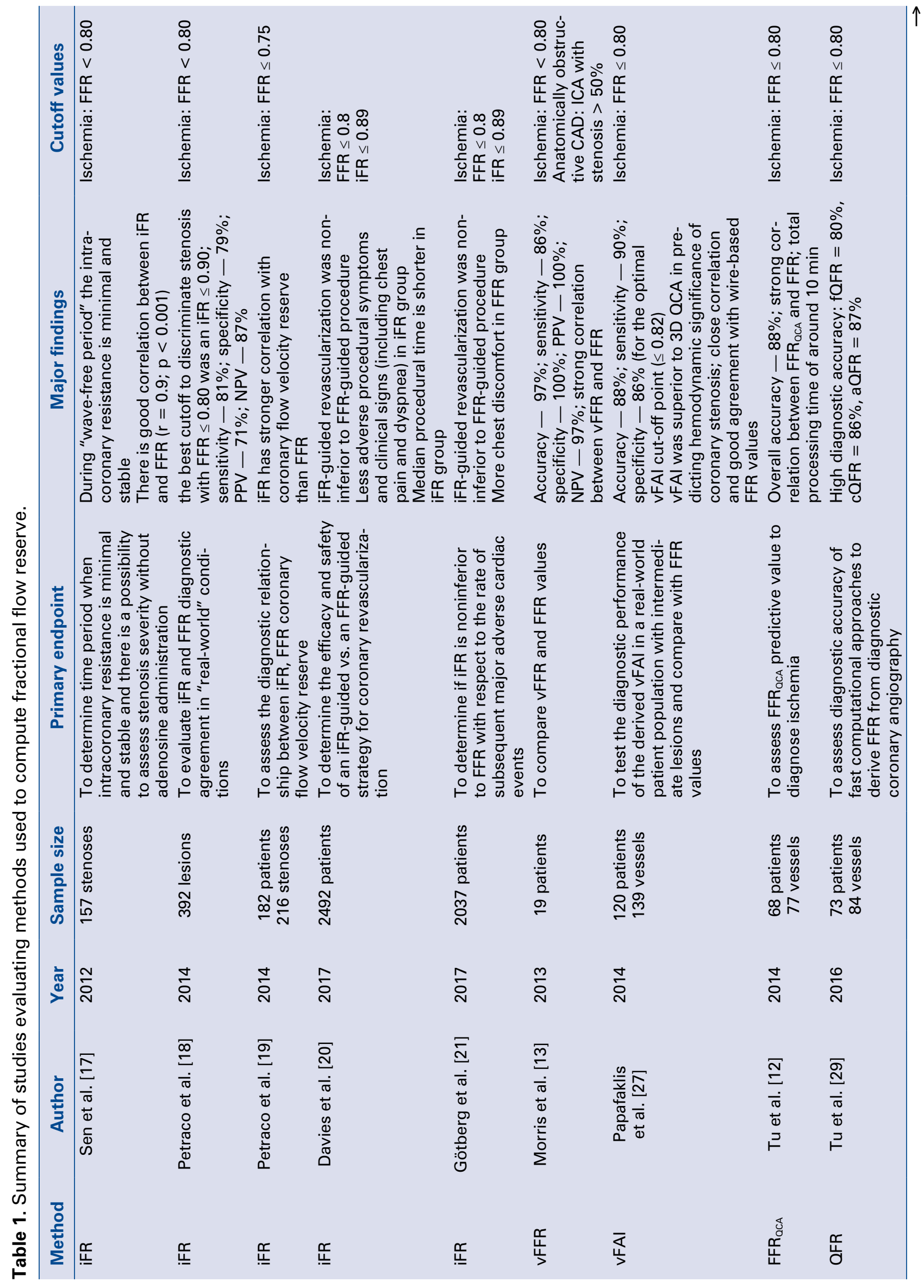




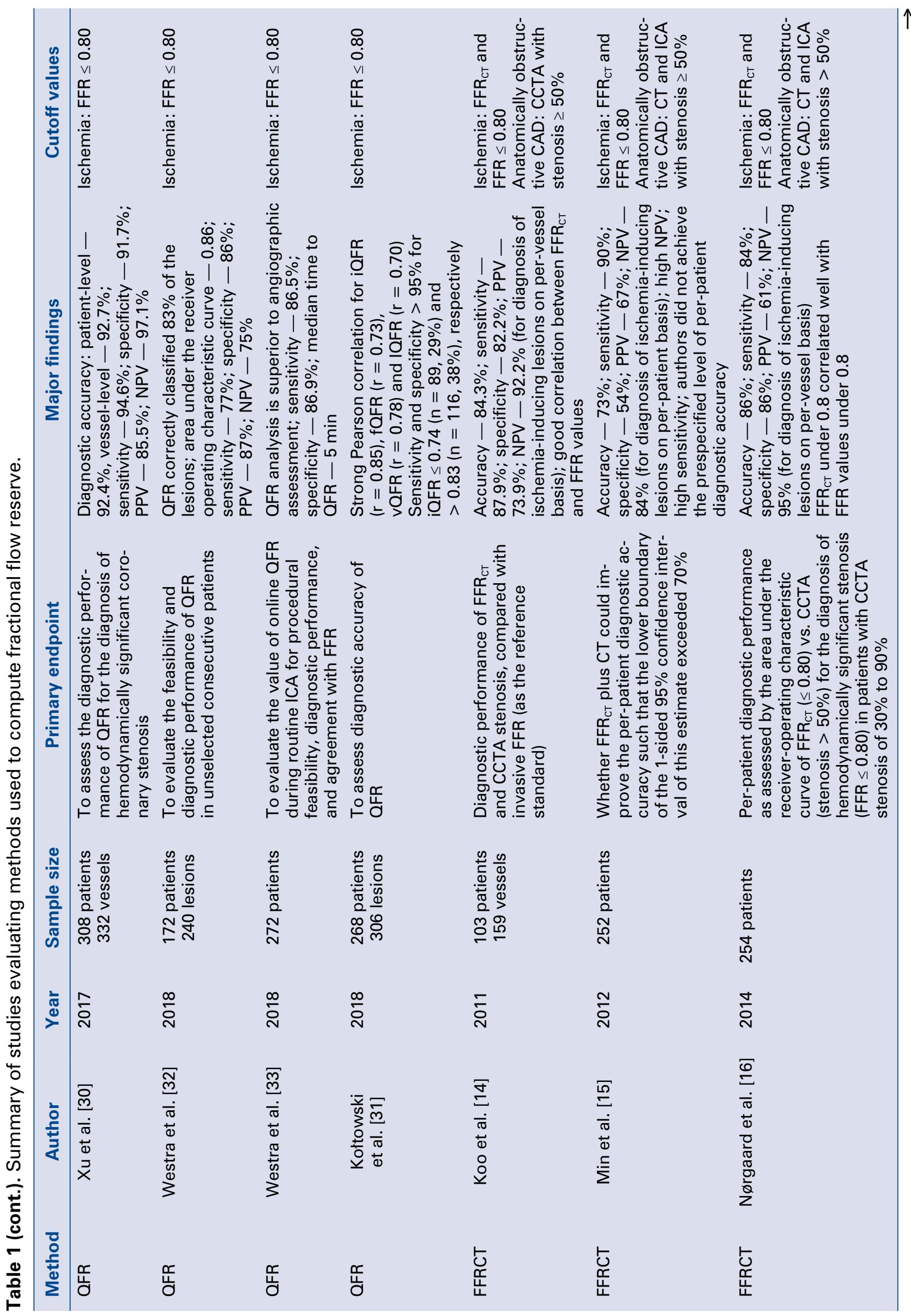




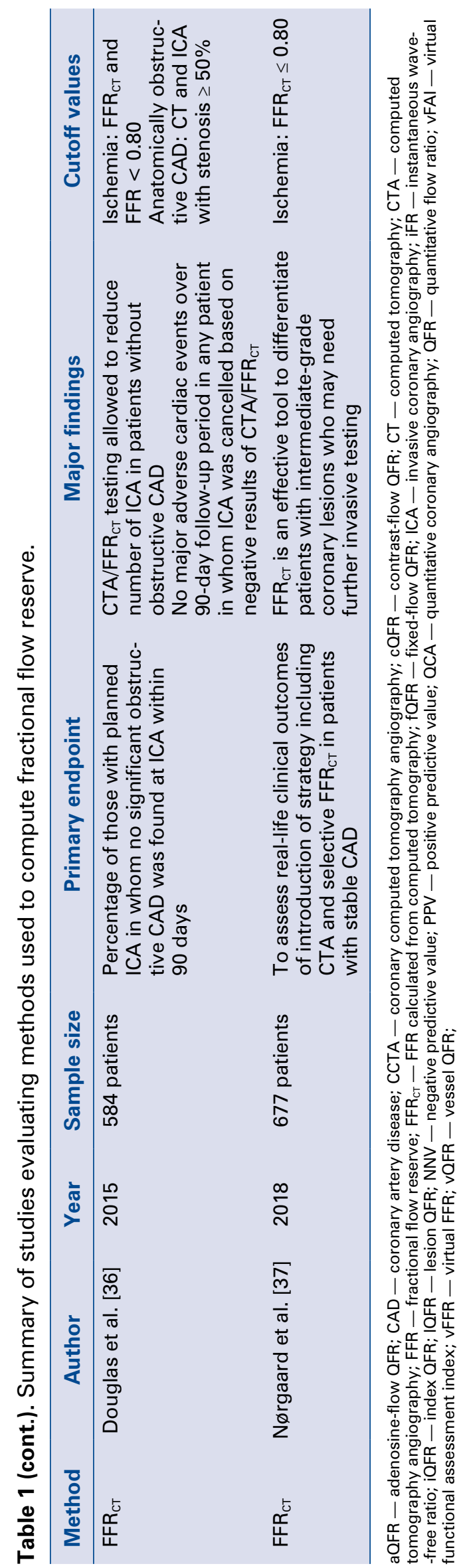

correlation between $\mathrm{FFR}_{\mathrm{CT}}$ and FFR values, with a slight underestimation by $\mathrm{FFR}_{\mathrm{CT}}(0.022 \pm 0.116$; $\mathrm{p}=0.016)$. Authors concluded that the addition of $\mathrm{FFR}_{\mathrm{CT}}$ to standard coronary CTA measurements might enhance diagnostic accuracy and this method's utility [14].

Min et al. [15] studied 252 stable patients who underwent coronary CTA, QCA and FFR measurements. Patients with a history of coronary artery bypass grafting or with suspected in-stent restenosis on the basis of CT were excluded. The $\mathrm{FFR}_{\mathrm{CT}}$ calculation was also based on coronary CTA. One analysis took up to 6 hours. Authors reported $\mathrm{FFR}_{\mathrm{CT}}$ 's accuracy of $73 \%$, sensitivity of $90 \%$, specificity of $54 \%$, PPV of $67 \%$, and NPV of $84 \%$ for diagnosis of ischemia-inducing lesions on a per-patient basis. The study did not achieve its pre-specified level of per-patient diagnostic accuracy, however, it showed that adding $\mathrm{FFR}_{\mathrm{CT}}$ analysis to plain CTA assessment improved diagnostic accuracy. Authors emphasized that $\mathrm{FFR}_{\mathrm{CT}}$ had high negative predictive value and high sensitivity, indicating that coronary angiogram is not needed when $\mathrm{FFR}_{\mathrm{CT}}$ 's results are normal, despite significant stenosis in CTA [15].

A refined version of $\mathrm{FFR}_{\mathrm{CT}}$ calculation was evaluated by Nørgaard et al. [16] who studied 254 patients with coronary CTA, QCA and FFR measurements. The new approach was significantly quicker with a mean time to results of less than $4 \mathrm{~h}$ (depending on CT scan quality and CAD burden). On a per-vessel basis, authors found diagnostic accuracy of $86 \%$, sensitivity of $84 \%$, specificity of $86 \%$, PPV of $61 \%$, and NPV of $95 \%$ for $\mathrm{FFR}_{\mathrm{CT}}$ under 0.8 , which correlated well with FFR values under 0.8 . They concluded that $\mathrm{FFR}_{\mathrm{CT}}$ has high diagnostic performance compared with standard FFR measurements [16].

The multicenter Prospective Longitudinal Trial of $\mathrm{FFR}_{\mathrm{CT}}$ : Outcome and Resource Impacts (PLATFORM) trial evaluated $\mathrm{FFR}_{\mathrm{CT}}$ guided revascularization looking at clinical outcomes, cost/ /resource utilization and quality of life. Overall 584 patients with new onset of chest pain were included. Patients were randomized to standard evaluation (usual care arm) and CTA/FFR $\mathrm{CT}_{\mathrm{CT}}$ testing. In the usual care arm, significantly more patients who underwent coronary angiography had no obstructive $\mathrm{CAD}$ when compared to $\mathrm{CTA} / \mathrm{FFR}_{\mathrm{CT}}$ care $\operatorname{arm}(73.3 \%$ vs. $12.4 \% ; \mathrm{p}<0.0001)$. This observation was further confirmed in a propensity score matching analysis of 148 pairs (72\% vs. $12 \%$; p < $<0.0001)$. Most importantly there were no major adverse cardiac events over the 90-day follow-up 
Table 2. Comparison of alternative methods of functional assessment of intermediate stenosis.

\begin{tabular}{lcccc}
\hline Comparator & FFR & iFR & QFR & FFR $_{\text {CT }}$ \\
\hline Invasiveness: & & & & + \\
$\quad$ Contrast & + & + & + & - \\
Invasive coronary angiography & + & + & - & - \\
Pressure wire & + & - & - & - \\
Adenosine & + & $5-7$ min* $^{*}$ & $3-5$ min $^{*}$ & $4-6 \mathrm{~h}^{*}$ \\
Data acquisition and processing time & $8-10$ min $^{*}$ & Online & Online & Offline \\
Online/offline processing & +++ & ++ & + & ++++ \\
Costs & & + & + \\
\hline
\end{tabular}

*Excluding standard invasive coronary angiography time and standard computed tomography angiography time; FFR — fractional flow reserve; $\mathrm{FFR}_{\mathrm{CT}}$ - FFR calculated from computed tomography; iFR — instantaneous wave-free ratio; QFR - quantitative flow ratio

period for any patient in whom ICA was canceled based on negative results of the CTA/FFR ${ }_{\mathrm{CT}}[36]$.

Further confirmation of $\mathrm{FFR}_{\mathrm{CT}}$ diagnostic value comes from a recently published cohort of almost 700 patients, who underwent $\mathrm{FFR}_{\mathrm{CT}}$ evaluation. The composite endpoint included all-cause death, MI, hospitalization for unstable angina, and unplanned revascularization. Patients were divided into four groups: 1 ) patients with coronary stenosis $<30 \%$ in CTA, who received optimal medical treatment (OMT); 2) patients with $\mathrm{FFR}_{\mathrm{CT}}>0.8$, who also received OMT; 3 ) patients with $\mathrm{FFR}_{\mathrm{CT}}$ $\leq 0.80$, who did not undergo any further testing and received OMT; 4) patients with $\mathrm{FFR}_{\mathrm{CT}} \leq 0.80$, who on the top of OMT were referred to ICA. Risk of MI was higher in group 3 than in group 4 ( $8 \%$ vs. $1.3 \%$; $<<0.001$ ), indicating that $\mathrm{FFR}_{\mathrm{CT}}$ is an effective diagnostic tool to differentiate patients with intermediate coronary lesions who may benefit from invasive treatment [37].

In conclusion, the $\mathrm{CTA} / \mathrm{FFR}_{\mathrm{CT}}$ analysis is a safe diagnostic method characterized however, by moderate diagnostic value. In patients already scheduled for CTA, adding $\mathrm{FFR}_{\mathrm{CT}}$ does not require additional imaging, radiation or medication [14-16]. Limitations of this method include long post-processing time, precluding online analysis and high cost. Additionally, the CTA dataset must be sent to a core laboratory to calculate FFR values. This is expensive and time-consuming. What is more, $\mathrm{FFR}_{\mathrm{CT}}$ is feasible only in CTA eligible patients, precluding a significant share of the CAD population, such as patients with massive calcifications, atrial fibrillation, previous stent implantation and others [38]. Moreover, vessel size may affect $\mathrm{FFR}_{\mathrm{CT}}$ values as well. Recently Gaur et al. [39] proved that volume-to-mass ratio, defined as total coronary vessel lumen volume relative to left ventricular mass, has a statistically significant influence on $\mathrm{FFR}_{\mathrm{CT}}$ 's accuracy and specificity.

\section{Conclusions}

Functional assessment of coronary arteries remains a gold standard in the diagnosis of patients with intermediate coronary artery stenosis. In current clinical practice, the adoption of traditional wire-based FFR technology is slow and limited by clinical safety and economic constraints. QFR and $\mathrm{FFR}_{\mathrm{CT}}$ are the new, less-/non-invasive computational methods that have recently emerged as promising diagnostic tools. The currently available body of evidence, though limited, provides solid grounds in recognizing these technologies as strong candidates to reduce the number of wirebased FFR examinations (Table 1). Advantages and disadvantages of above-mentioned diagnostic tools are summed up in Table 2.

It is thought herein, that all these methods will find their place in the management of patients with CAD. It seems that $\mathrm{QFR}$ and $\mathrm{FFR}_{\mathrm{CT}}$ should be perceived as more complementary, rather than competitive modalities. While $\mathrm{FFR}_{\mathrm{CT}}$ may lead to better identification of patients who would not benefit from ICA investigation, QFR may be used on-line to assess the hemodynamic significance of a lesion during ICA and eliminate risks associated with wiring of a coronary artery. It is essential to utilize cut-off values in which QFR has excellent agreement with FFR measurements ("grey-zone" concept). If results of the upcoming clinical validation will be positive, one may foresee a change in the current diagnostic algorithm by incorporating 


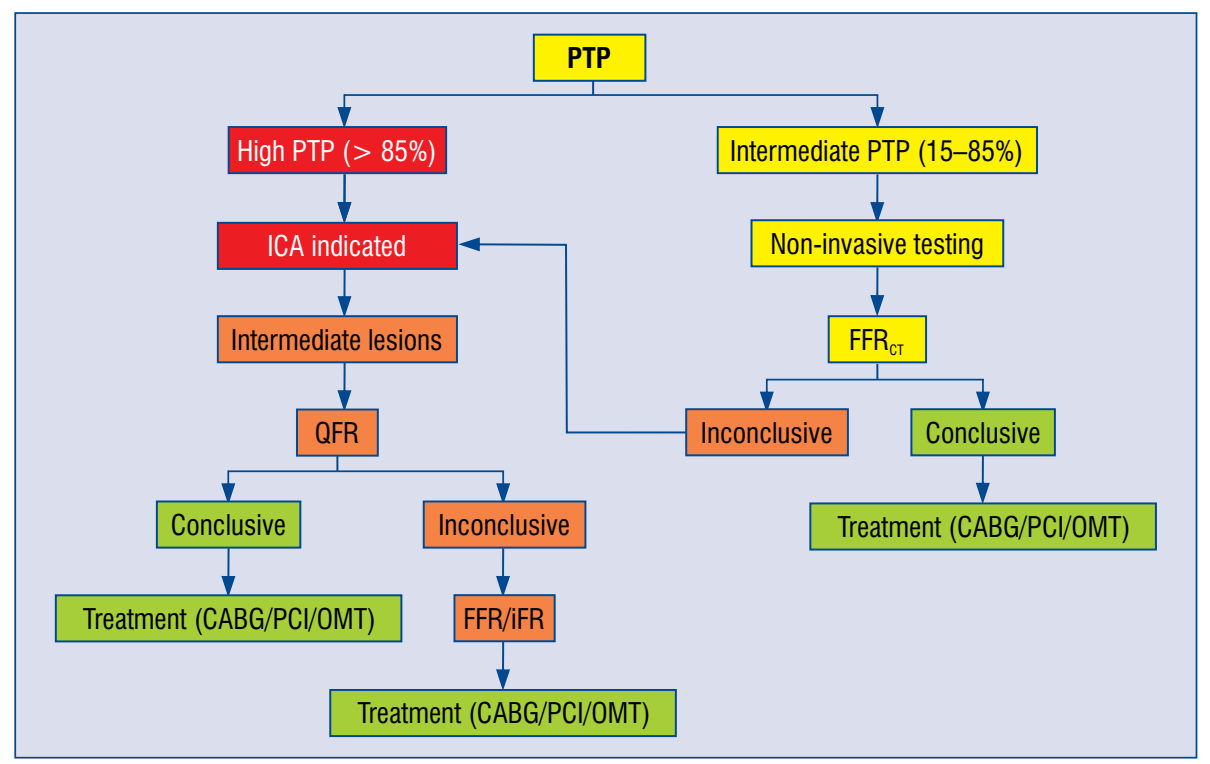

Figure 5. Proposed diagnostic algorithm; PTP — pre-test-probability of coronary artery disease; QFR — quantitative flow ratio; FFR — fractional flow reserve; iFR — instantaneous wave-free ratio; $F_{F R}$ - FFR calculated from computed tomography; CABG — coronary artery bypass grafting; $\mathrm{PCl}$ - percutaneous coronary intervention; OMT — optimal medical treatment.

alternative methods for functional assessment of intermediate coronary lesions (Fig. 5).

\section{Conflict of interest: None declared}

\section{References}

1. Mendis S, Davis S, Norrving Bo. Organizational update: the world health organization global status report on noncommunicable diseases 2014; one more landmark step in the combat against stroke and vascular disease. Stroke. 2015; 46(5): e121-e122, doi: 10.1161/STROKEAHA.115.008097, indexed in Pubmed: 25873596.

2. Global, regional, and national age-sex specific all-cause and cause-specific mortality for 240 causes of death, 1990-2013: a systematic analysis for the Global Burden of Disease Study 2013. The Lancet. 2015; 385(9963): 117-171, doi: 10.1016/ s0140-6736(14)61682-2.

3. Toth G, Toth B, Johnson N, et al. Revascularization decisions in patients with stable angina and intermediate lesions. Circ Cardiovasc Interv. 2014; 7(6): 751-759, doi: 10.1161/circinterventions. 114.001608

4. Biały D, Wawrzyńska M, Arkowski J, et al. Multimodality imaging of intermediate lesions: Data from fractional flow reserve, optical coherence tomography, near-infrared spectroscopy-intravascular ultrasound. Cardiol J. 2018; 25(2): 196-202, doi: 10.5603/ CJ.a2017.0082, indexed in Pubmed: 28714527.

5. Dattilo PB, Prasad A, Honeycutt E, et al. Contemporary patterns of fractional flow reserve and intravascular ultrasound use among patients undergoing percutaneous coronary intervention in the United States: insights from the National Cardiovascular Data Registry. J Am Coll Cardiol. 2012; 60(22): 2337-2339, doi: 10.1016/j.jacc.2012.08.990, indexed in Pubmed: 23194945.

6. Dehmer GJ, Weaver D, Roe MT, et al. A contemporary view of diagnostic cardiac catheterization and percutaneous coronary intervention in the United States: a report from the CathPCI
Registry of the National Cardiovascular Data Registry, 2010 through June 2011. J Am Coll Cardiol. 2012; 60(20): 2017-2031, doi: 10.1016/j.jacc.2012.08.966, indexed in Pubmed: 23083784.

7. Härle T, Zeymer U, Hochadel M, et al. Real-world use of fractional flow reserve in Germany: results of the prospective ALKK coronary angiography and PCI registry. Clin Res Cardiol. 2017; 106(2): 140-150, doi: 10.1007/s00392-016-1034-5, indexed in Pubmed: 27599974.

8. Ochała A, Siudak $Z$, Legutko J, et al. Percutaneous interventions in cardiology in Poland in the year 2014. Summary report of the Association of Cardiovascular Interventions of the Polish Cardiac Society AISN PTK. Postepy Kardiol Interwencyjnej. 2015; 11(3): 177-181, doi: 10.5114/pwki.2015.54009, indexed in Pubmed: 26677356.

9. Kumsars I, Narbute I, Thuesen L, et al. Side branch fractional flow reserve measurements after main vessel stenting: a NordicBaltic Bifurcation Study III substudy. EuroIntervention. 2012; 7(10): 1155-1161, doi: 10.4244/EIJV7I10A186, indexed in Pubmed: 22334314.

10. Curzen N, Rana O, Nicholas Z, et al. Does routine pressure wire assessment influence management strategy at coronary angiography for diagnosis of chest pain?: the RIPCORD study. Circ Cardiovasc Interv. 2014; 7(2): 248-255, doi: 10.1161/CIRCINTERVENTIONS.113.000978, indexed in Pubmed: 24642999.

11. Park E, Price A, Vidovich MI. Adenosine-induced atrial fibrillation during fractional flow reserve measurement. Cardiol J. 2012 19(6): 650-651, indexed in Pubmed: 23224932.

12. Tu S, Barbato E, Köszegi $Z$, et al. Fractional flow reserve calculation from 3-dimensional quantitative coronary angiography and TIMI frame count: a fast computer model to quantify the functional significance of moderately obstructed coronary arteries. JACC Cardiovasc Interv. 2014; 7(7): 768-777, doi: 10.1016/j. jcin.2014.03.004, indexed in Pubmed: 25060020.

13. Morris PD, Ryan D, Morton AC, et al. Virtual fractional flow reserve from coronary angiography: modeling the significance of coronary lesions: results from the VIRTU-1 (VIRTUal Fractional Flow Reserve From Coronary Angiography) study. JACC Cardiovasc Interv. 2013; 6(2): 149-157, doi: 10.1016/j.jcin.2012.08.024, indexed in Pubmed: 23428006. 
14. Koo BK, Erglis A, Doh JH, et al. Diagnosis of ischemia-causing coronary stenoses by noninvasive fractional flow reserve computed from coronary computed tomographic angiograms. Results from the prospective multicenter DISCOVER-FLOW (Diagnosis of Ischemia-Causing Stenoses Obtained Via Noninvasive Fractional Flow Reserve) study. J Am Coll Cardiol. 2011; 58(19): 1989-1997, doi: 10.1016/j.jacc.2011.06.066, indexed in Pubmed: 22032711.

15. Min JK, Leipsic J, Pencina MJ, et al. Diagnostic accuracy of fractional flow reserve from anatomic CT angiography. JAMA. 2012; 308(12): 1237-1245, doi: 10.1001/2012.jama.11274, indexed in Pubmed: 22922562.

16. Nørgaard BL, Leipsic J, Gaur S, et al. Diagnostic performance of noninvasive fractional flow reserve derived from coronary computed tomography angiography in suspected coronary artery disease: the NXT trial (Analysis of Coronary Blood Flow Using CT Angiography: Next Steps). J Am Coll Cardiol. 2014; 63(12): 1145-1155, doi: 10.1016/j.jacc.2013.11.043, indexed in Pubmed: 24486266.

17. Sen S, Escaned J, Malik IS, et al. Development and validation of a new adenosine-independent index of stenosis severity from coronary wave-intensity analysis: results of the ADVISE (ADenosine Vasodilator Independent Stenosis Evaluation) study. J Am Coll Cardiol. 2012; 59(15): 1392-1402, doi: 10.1016/j. jacc.2011.11.003, indexed in Pubmed: 22154731.

18. Petraco R, Al-Lamee R, Gotberg M, et al. Real-time use of instantaneous wave-free ratio: results of the ADVISE in-practice: an international, multicenter evaluation of instantaneous wavefree ratio in clinical practice. Am Heart J. 2014; 168(5): 739-748, doi: 10.1016/j.ahj.2014.06.022, indexed in Pubmed: 25440803.

19. Petraco R, Hoef Tv, Nijjer S, et al. Baseline instantaneous wavefree ratio as a pressure-only estimation of underlying coronary flow reserve. Circ Cardiovasc Interv. 2014; 7(4): 492-502, doi: 10.1161/circinterventions.113.000926.

20. Davies JE, Sen S, Dehbi HM, et al. Use of the Instantaneous Wave-free Ratio or Fractional Flow Reserve in PCI. N Engl J Med. 2017; 376(19): 1824-1834.

21. Götberg M, Christiansen EH, Gudmundsdottir IJ, et al. Instantaneous wave-free ratio versus fractional flow reserve to guide PCI. N Engl J Med. 2017; 376(19): 1813-1823, doi: 10.1056/ NEJMoa1616540, indexed in Pubmed: 28317438.

22. Neumann FJ, Sousa-Uva M, Ahlsson A, et al. 2018 ESC/EACTS Guidelines on myocardial revascularization. Eur Heart J. 2018.

23. Patel M, Calhoon J, Dehmer G, et al. ACC/AATS/AHA/ASE/ ASNC/SCAI/SCCT/STS 2017 Appropriate Use Criteria for Coronary Revascularization in Patients With Stable Ischemic Heart Disease. J Nucl Cardiol. 2017; 24(5): 1759-1792, doi: 10.1007/ s12350-017-0917-9.

24. Lee JM, Park J, Hwang D, et al. Similarity and difference of resting distal to aortic coronary pressure and Instantaneous wave-free ratio. J Am Coll Cardiol. 2017; 70(17): 2114-2123, doi: 10.1016/j.jacc.2017.09.007, indexed in Pubmed: 29050558.

25. Kobayashi Y, Johnson NP, Zimmermann FM, et al. Agreement of the resting distal to Aortic Coronary pressure with the Instantaneous wave-free ratio. J Am Coll Cardiol. 2017; 70(17): 2105-2113, doi: 10.1016/j.jacc.2017.08.049, indexed in Pubmed: 29050557.

26. Van't Veer M, Pijls NHJ, Hennigan B, et al. Comparison of Different Diastolic Resting Indexes to iFR: Are They All Equal? J Am Coll Cardiol. 2017; 70(25): 3088-3096, doi: 10.1016/j. jacc.2017.10.066, indexed in Pubmed: 29268922.

27. Papafaklis MI, Muramatsu T, Ishibashi Y, et al. Fast virtual functional assessment of intermediate coronary lesions using routine angiographic data and blood flow simulation in humans: comparison with pressure wire - fractional flow reserve. EuroIntervention. 2014; 10(5): 574-583, doi: 10.4244/EIJY14M07_01, indexed in Pubmed: 24988003.

28. Lansky AJ, Pietras C. Fractional flow reserve from 3-dimensional quantitative coronary angiography: fresh light through an old window. JACC Cardiovasc Interv. 2014; 7(7): 778-780, doi: 10.1016/j.jcin.2014.05.002, indexed in Pubmed: 25060021.

29. Tu S, Westra J, Yang J, et al. Diagnostic accuracy of fast computational approaches to derive fractional flow reserve from diagnostic coronary angiography: the international multicenter FAVOR pilot study. JACC Cardiovasc Interv. 2016; 9(19): 2024-2035, doi: 10.1016/j.jcin.2016.07.013, indexed in Pubmed: 27712739.

30. Xu Bo, Tu S, Qiao S, et al. Diagnostic accuracy of angiography-based quantitative flow ratio measurements for online assessment of coronary stenosis. J Am Coll Cardiol. 2017; 70(25): 3077-3087, doi: 10.1016/j.jacc.2017.10.035, indexed in Pubmed: 29101020.

31. Kołtowski Ł, Zaleska M, Maksym J, et al. Quantitative flow ratio derived from diagnostic coronary angiography in assessment of patients with intermediate coronary stenosis: a wire-free fractional flow reserve study. Clin Res Cardiol. 2018; 107(9): 858-867, doi: 10.1007/s00392-018-1258-7, indexed in Pubmed: 30128817.

32. Westra J, Tu S, Winther S, et al. Evaluation of coronary artery stenosis by quantitative flow ratio during invasive coronary angiography: the WIFI II study (wire-free functional imaging II). Circ Cardiovasc Imaging. 2018; 11(3): e007107, doi: 10.1161/ CIRCIMAGING.117.007107, indexed in Pubmed: 29555835.

33. Westra J, Andersen BK, Campo G, et al. Diagnostic performance of in-procedure angiography-derived quantitative flow reserve compared to pressure-derived fractional flow reserve: the FAVOR II europe-japan study. J Am Heart Assoc. 2018; 7(14), doi: 10.1161/JAHA.118.009603, indexed in Pubmed: 29980523.

34. Spitaleri G, Tebaldi M, Biscaglia S, et al. Quantitative flow ratio identifies nonculprit coronary lesions requiring revascularization in patients with st-segment-elevation myocardial infarction and multivessel disease. Circ Cardiovasc Interv. 2018; 11(2): e006023, doi: 10.1161/CIRCINTERVENTIONS.117.006023, indexed in Pubmed: 29449325.

35. Chang Y, Chen L, Westra J, et al. Reproducibility of quantitative flow ratio: An inter-core laboratory variability study. Cardiol J. 2020; 27(3): 230-237, doi: 10.5603/CJ.a2018.0105, indexed in Pubmed: 30234896.

36. Douglas PS, Pontone G, Hlatky MA, et al. Clinical outcomes of fractional flow reserve by computed tomographic angiographyguided diagnostic strategies vs. usual care in patients with suspected coronary artery disease: the prospective longitudinal trial of FFR(CT): outcome and resource impacts study. Eur Heart J. 2015; 36(47): 3359-3367, doi: 10.1093/eurheartj/ehv444, indexed in Pubmed: 26330417.

37. Nørgaard BL, Terkelsen CJ, Mathiassen ON, et al. Coronary CT angiographic and flow reserve-guided management of patients with stable ischemic heart disease. J Am Coll Cardiol. 2018; 72(18): 2123-2134, doi: 10.1016/j.jacc.2018.07.043, indexed in Pubmed: 30153968.

38. Zarins CK, Taylor CA, Min JK. Computed fractional flow reserve (FFTCT) derived from coronary CT angiography. J Cardiovasc Transl Res. 2013; 6(5): 708-714, doi: 10.1007/s12265-013-9498-4, indexed in Pubmed: 23934536.

39. Gaur S, Taylor CA, Jensen JM, et al. FFR derived from coronary CT angiography in Nonculprit Lesions of patients with recent stemi. JACC Cardiovasc Imaging. 2017; 10(4): 424-433, doi: 10.1016/j.jcmg.2016.05.019, indexed in Pubmed: 27743953. 